\title{
Immunohistochemical analysis of SOX2 expression in small-cell neuroendocrine carcinoma of the endometrium
}

\author{
YUSUKE EBISU $^{1}$, MITSUAKI ISHIDA ${ }^{1}$, TOMOMI MIZOKAMI ${ }^{2}$, \\ MASATO KITA $^{2}$, HIDETAKA OKADA ${ }^{2}$ and KOJI TSUTA ${ }^{1}$ \\ Departments of ${ }^{1}$ Pathology and Laboratory Medicine and ${ }^{2}$ Obstetrics and Gynaecology, \\ Kansai Medical University, Hirakata, Osaka 573-1010, Japan
}

Received August 26, 2019; Accepted April 10, 2020

DOI: $10.3892 / \mathrm{mco} .2020 .2051$

\begin{abstract}
Small-cell neuroendocrine carcinoma (NEC) of the endometrium is an extremely rare and highly aggressive carcinoma. Sex-determining region Y-box 2 (SOX2) is a master transcription factor regulating the self-renewal, maintenance of stem cell properties and pluripotency of embryonic stem cells, and recent studies revealed that SOX2 plays important roles in cancer growth and progression in several types of carcinomas, including small-cell neuroendocrine carcinoma (NEC) of the lung and oesophagus. Few studies to date have analysed the association between SOX2 and endometrioid carcinoma, whereas the expression of SOX2 in small-cell NEC of the endometrium has not been investigated. The aim of the present study was to analyse the expression status of SOX2, p16 and paired-box gene (PAX) 8, a useful Müllerian marker, in endometrial small-cell NEC. A total of 4 patients with small-cell NEC of the endometrium were enrolled (median age, 70 years). Immunohistochemical studies revealed SOX2 expression in 3 patients and p16 expression in all patients. No patients exhibited positive immunoreactivity for PAX8. SOX2 expression has been reported to be associated with the pathogenesis of small-cell NEC of the oesophagus. Therefore, the results of the present study indicated that SOX2 expression plays an important role in the development of small-cell NEC of the endometrium and the oesophagus. Moreover, expression of p16 and loss of PAX8 do not indicate the origin of small-cell NEC of the endometrium.
\end{abstract}

\footnotetext{
Correspondence to: Dr Mitsuaki Ishida, Department of Pathology and Laboratory Medicine, Kansai Medical University, 2-5-1 Shinmachi, Hirakata, Osaka 573-1010, Japan

E-mail: ishidamt@hirakata.kmu.ac.jp
}

Key words: small-cell neuroendocrine carcinoma, endometrium, sex-determining region Y-box 2, p16, paired-box gene 8

\section{Introduction}

Neuroendocrine tumours rarely occur in the genital tract, and endometrial neuroendocrine tumours in particular are extremely rare. Neuroendocrine tumours are classified as low-grade neuroendocrine tumour or high-grade neuroendocrine carcinoma (NEC), with the latter further subclassified as small-and large-cell NEC (1). Approximately 100 cases of small-cell NEC of the endometrium have been reported in the English language literature (2,3), and this type of tumour shows an aggressive clinical course.

Sex-determining region Y-box 2 (SOX2) is a member of the SOX family and is a master transcription factor of the self-renewal, maintenance of stem cell properties, and pluripotency of embryonic stem cells (4). Its expression is tightly regulated during embryonic development. It has been reported that SOX2 also plays important roles in cell survival and cancer growth and progression in several types of carcinomas, such as lung, breast, gastric and pancreatic cancers, as well as malignant melanoma (5-9).

A limited number of studies have addressed the role of SOX2 expression in endometrial cancer (10-12). A recent study detected SOX 2 expression in $17 \%$ of patients with endometrial carcinoma, which was significantly correlated with high histological grade and poor prognosis (10). Moreover, a high frequency of SOX2 expression has been reported in small- and large-cell NECs of the lung (5) and small-cell NEC of the oesophagus (13). However, its expression and significance in small-cell NEC of the endometrium have not been examined. The aim of the present study was to analyse the expression profiles of SOX2 in small-cell NEC of the endometrium, which were compared with those of p16 and paired-box gene (PAX) 8, a useful Müllerian marker.

\section{Patients and methods}

Patients and samples. The pathology archives of Kansai Medical University Hospital between January 2006 and December 2017 were reviewed. Patients with a histopathological diagnosis of endometrial small-cell NEC were enrolled in the present study. The diagnosis of small-cell NEC was independently confirmed by two diagnostic pathologists. The majority of the patients evaluated in the 
present study were also included in our previous study on the cytological characteristics of endometrial small-cell NEC (14). Patients who had been administered preoperative chemotherapy were excluded.

The present study was conducted in accordance with the principles outlined in the Declaration of Helsinki, and the study protocol was approved by the Institutional Review Board of Kansai Medical University Hospital (approval no. 2016646). The need for informed consent was waived due to the retrospective design of the study.

Immunohistochemistry. Formalin-fixed and paraffinembedded blocks of resected specimens of small-cell NEC of the endometrium were cut into $4-\mu \mathrm{m}$ sections, deparaffinized and rehydrated. Immunohistochemical analyses were performed using autostainers (Discovery ULTRA System, Link 48; Roche Diagnostics, Dako Cytomation) according to the manufacturer's instructions. The primary antibodies used were mouse monoclonal antibody against chromogranin A (clone LK2H10, Cell Marque, dilution 1:500), mouse monoclonal antibody against p16 (clone. E6H4, Roche Diagnostics, prediluted), mouse monoclonal antibody against PAX8 (clone. PAX8R1, Abcam, dilution 1:100), rabbit polyclonal antibody against SOX2 (cat. no. PM056, Medial and Biological Laboratories Co., Ltd., dilution 1:500), and mouse monoclonal antibody against synaptophysin (clone 27G12, Nichirei Bioscience, prediluted). Immunohistochemical staining of p16, PAX8 and SOX2 was quantitatively analysed as the proportion of positive neoplastic cells. p16 expression was evaluated as nuclear and/or cytoplasmic stainings, and PAX8 and SOX2 were evaluated as nuclear staining. The expression status of chromogranin A and synaptophysin was evaluated as the presence of positive neoplastic cells (more than 1\%). Immunohistochemical staining results were independently evaluated by at least two researchers.

\section{Results}

Clinicopathological characteristics. The present study included 4 patients with small-cell NEC of the endometrium. The clinicopathological characteristics of the present series are summarized in Table I. The median age of the patients was 70 years (range, 61-73 years). All the patients were post-menopausal.

The characteristic histopathological features of small-cell NEC are shown in Fig. 1. Diffuse proliferation of neoplastic cells with round to oval nuclei showing a salt and pepper chromatin pattern and high nuclear/cytoplasmic ratio were observed. Mitotic figures (more than 10 mitotic figures/10 high-power fields) and apoptotic bodies were frequently observed. A conventional endometrioid carcinoma component was detected in 1 patient (Case 4).

Immunohistochemical characteristics. The immunohistochemical results of the present study are summarized in Table I. SOX2 was expressed in 3 of the 4 patients, and the median percentage of positive neoplastic cells in positive patients was $70 \%$ (range, 30-80\%; Fig. 2A). p16 was expressed in all cases (100\% of neoplastic cells in all cases; Fig. 2B). None of the cases exhibited positive immunoreactivity for
PAX8 in the small-cell NEC component, although the conventional endometrioid carcinoma component in case 4 showed positive immunoreactivity for this marker.

Chromogranin A and synaptophysin expression was noted in 4 and 3 cases, respectively.

\section{Discussion}

The present study demonstrated that SOX2 was expressed in 3 of 4 patients with small-cell NEC of the endometrium (the median proportion of positive neoplastic cells was $70 \%$ in positive patients), p16 was diffusely expressed in all cases, and none of the cases showed positive immunoreactivity for PAX8.

SOX2 is a transcription factor that plays an important role in the growth and progression of several types of carcinomas (5-9). The role of SOX2 expression in small-cell NEC of some organs has been previously analysed $(13,15)$. A recent study revealed high SOX2 expression in small-cell NEC of the oesophagus and the lung, indicating that SOX2 plays a pivotal role in the development of small-cell NEC in these locations (13). In the present study, 3 of 4 patients with endometrial small-cell NEC exhibited positive immunoreactivity for SOX2. Accordingly, SOX2 may play an important role in the pathogenesis of small-cell NEC of the endometrium, lung and oesophagus, as only $17 \%$ of patients with conventional endometrial carcinoma, particularly those with high histological grade, express this marker (10).

p16 plays important role in cell cycle regulation, and its expression is observed in most cases of human papillomavirus-related cervical carcinoma (16). It is well-known that p16 is expressed in high-grade endometrial carcinomas, including serous carcinoma (16). The largest case series of small-cell NEC of the endometrium revealed p16 expression in $5 / 5$ cases (2), which was consistent with the results obtained in the present study (4/4 cases); therefore, p16 expression appears to be a common finding in high-grade endometrial carcinomas, including small-cell NEC. Moreover, p16 expression has been reported in small-cell NEC of cervical origin (17); therefore, positive immunoreactivity for this marker in small-cell NEC does not indicate cervical origin.

PAX8 is a transcription marker associated with the organogenesis of the Müllerian system, thyroid and kidney (18). Epithelial cells in the genital tract and conventional endometrioid carcinoma cells commonly express this marker (18). However, no samples from small-cell NECs of the endometrium exhibited positive immunoreactivity for PAX8 in the present study, although the conventional endometrioid carcinoma component was positive in 1 case. This agrees with the results of a previous study, in which PAX8 expression was detected in 2/6 cases of small-cell NEC of the endometrium (2). These results suggest that loss of PAX8 may be a common finding in small-cell NEC of the endometrium, and PAX8 is not a reliable marker of endometrial origin when diagnosing small-cell NEC of unknown primary site (2).

In conclusion, the present study demonstrated that SOX2 may play an important role in the development of small-cell NEC of the endometrium, as well as that of the lung and oesophagus. Expression of p16 or loss of PAX8 expression are common findings associated with this type of tumour, and do not indicate the origin of small-cell NEC. The present study 
Table I. Clinicopathological and immunohistochemical characteristics of small-cell neuroendocrine carcinoma of the endometrium.

\begin{tabular}{|c|c|c|c|c|c|c|c|}
\hline \multirow[b]{2}{*}{ Case no. } & \multirow[b]{2}{*}{ Age (years) } & \multirow{2}{*}{$\begin{array}{c}\text { Endometrioid } \\
\text { carcinoma } \\
\text { component }\end{array}$} & \multicolumn{2}{|c|}{$\begin{array}{c}\text { Immunohistochemical } \\
\text { characteristics }\end{array}$} & \multirow[b]{2}{*}{ PAX8 (\%) } & \multirow[b]{2}{*}{ Chromogranin A } & \multirow[b]{2}{*}{ Synaptophysin } \\
\hline & & & SOX2 (\%) & p16 (\%) & & & \\
\hline 1 & 73 & - & 70 & 100 & 0 & + & + \\
\hline 2 & 72 & - & 30 & 100 & 0 & + & - \\
\hline 3 & 61 & - & 80 & 100 & 0 & + & + \\
\hline 4 & 68 & + & 0 & 100 & 0 & + & + \\
\hline
\end{tabular}

SOX2, sex-determining region Y-box 2; PAX8, paired-box gene 8.

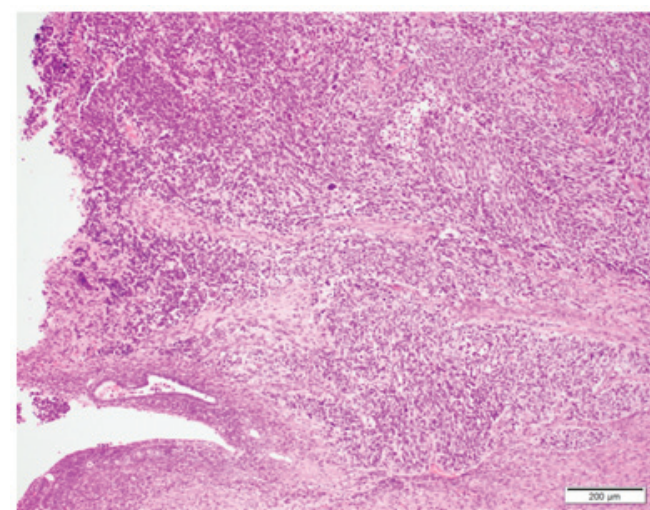

Figure 1. Typical histopathological characteristics of small-cell neuroendocrine carcinoma of the endometrium (case 3). Diffuse proliferation of neoplastic cells with round to oval nuclei exhibiting a salt-and-pepper chromatin pattern and lack of conspicuous nucleoli, with a high nuclear/cytoplasmic ratio. Non-neoplastic atrophic endometrial glands are observed in the lower left (haematoxylin and eosin staining; magnification, x100).

included a limited number of patients with small-cell NEC of the endometrium; therefore, additional studies are needed to fully elucidate the expression profiles of immunohistochemical markers and pathogenesis of small-cell NEC of the endometrium.

\section{Acknowledgements}

Not applicable.

\section{Funding}

No funding was received.

\section{Availability of data and materials}

All data generated or analysed during the present study are included in this published article.

\section{Authors' contributions}

YE and MI conceived and designed the study. YE, MI, TM, MK, HO and KT acquired and analysed the data. YE and MI drafted the manuscript and designed the figures. The final
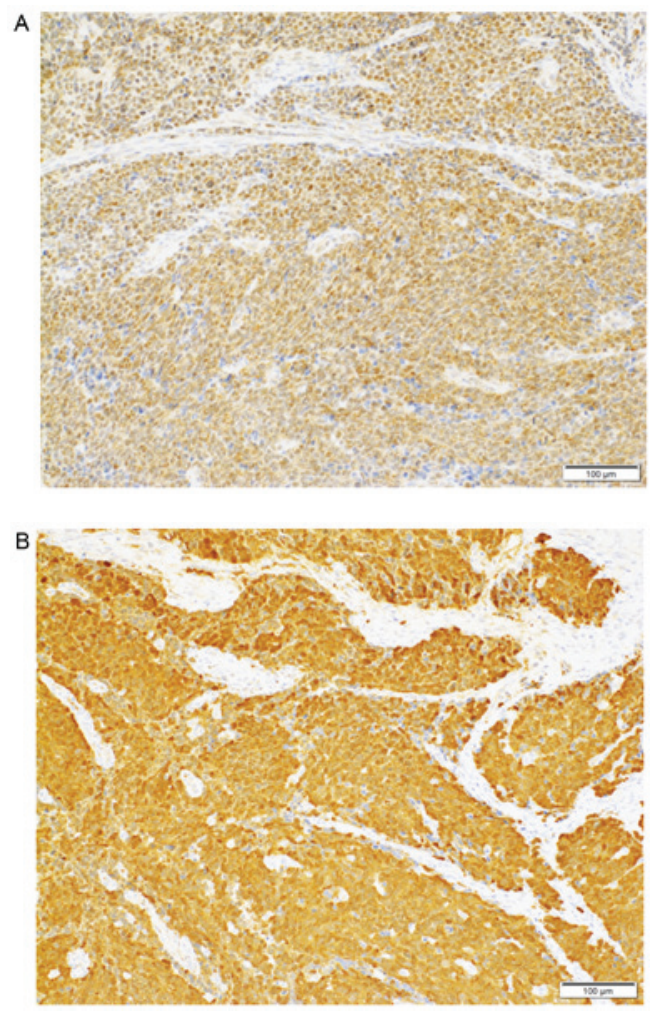

Figure 2. Immunohistochemical characteristics of small cell-neuroendocrine carcinoma of the endometrium (case 3). (A) Sex-determining region Y-box 2 is expressed in the nuclei of neoplastic cells (magnification, $\mathrm{x} 200$ ). (B) p16 is diffusely expressed in neoplastic cells (magnification, x200).

version of the manuscript has been read and approved by all authors.

\section{Ethics approval and consent to participate}

The present study was conducted in accordance with the principles outlined in the Declaration of Helsinki, and the study protocol was approved by the Institutional Review Board of Kansai Medical University Hospital (approval no. 2016646).

\section{Patient consent for publication}

The need for informed consent was waived due to the retrospective design of the study. 


\section{Competing interests}

The authors declare that they have no competing interests.

\section{References}

1. Zaio R, Carinelli SG, Ellenson LH, Eng C, Katabuchi H, Konishi I,Lax S, Matias-Guiu X, Mutter GL, Peters WA III, et al: Epithelial tumours and precursors. In: Kurman RJ, Carcangiu ML, Herrington S and Young RH (eds). WHO classification of tumours of female reproductive organs. 4th edition. Lyon, IARC, pp125-135, 2014.

2. Pocrnich CE, Ramalingam P, Euscher ED and Malpica A: Neuroendocrine carcinoma of the endometrium: A clinicopathologic study of 25 cases. Am J Surg Pathol 40: 577-586, 2016.

3. Ishida M, Iwamoto N, Nakagawa T, Kaku S, Iwai M, Kagotani A, Takahashi K, Murakami T and Okabe H: Small cell carcinoma of the endometrium: A case report with emphasis on the cytological features. Int J Clin Exp Pathol 7: 3332-3337, 2014.

4. Adachi K, Nikaido I, Ohta H, Ohtsuka S, Ura H, Kadota M, Wakayama T, Ueda HR and Niwa H: Context-dependent wiring of Sox 2 regulatory networks for self-renewal of embryonic and trophoblast stem cells. Mol Cell 52: 380-392, 2013.

5. Sholl LM, Long KB and Hornick JL: Sox2 expression in pulmonary non-small cell and neuroendocrine carcinomas. Appl Immunohistochem Mol Morphol 18: 55-61, 2010.

6. Shima H, Kutomi G, Satomi F, Maeda H, Hirohashi Y, Hasegawa T, Mori M, Torigoe T and Takemasa I: SOX2 and ALDH1 as predictors of operable breast cancer. Anticancer Res 36: 2945-2953, 2016.

7. Basati G, Mohammadpour H and Emami Razavi A: Association of high expression levels of SOX2, NANOG, and OCT4 in gastric cancer tumor tissues with progression and poor prognosis. J Gastrointest Cancer 51: 41-47, 2020.

8. Herreros-Villanueva M, Bujanda L, Billadeau DD and Zhang JS: Embryonic stem cell factors and pancreatic cancer. World J Gastroenterol 20: 2247-2254, 2014.

9. Santini R, Pietrobono S, Pandolfi S, Montagnani V, D'Amico M, Penachioni JY, Vinci MC, Borgognoni L and Stecca B: SOX2 regulates self-renewal and tumorigenicity of human melanoma-initiating cells. Oncogene 33: 4697-4708, 2014.

10. Yamawaki K, Ishiguro T, Mori Y, Yoshihara K, Suda K, Tamura R, Yamaguchi M, Sekine M, Kashima K, Higuchi M, et al: Sox2-dependent inhibition of p21 is associated with poor prognosis of endometrial cancer. Cancer Sci 108: 632-640, 2017.
11. Lee CJ, Sung PL, Kuo MH, Tsai MH, Wang CK, Pan ST, Chen YJ, Wang PH, Wen KC and Chou YT: Crosstalk between SOX2 and cytokine signaling in endometrial carcinoma. Sci Rep 8: 17550, 2018.

12. Pityński K, Banas T, Pietrus M, Milian-Ciesielska K, Ludwin A and Okon K: SOX-2, but not Oct4, is highly expressed in early-stage endometrial adenocarcinoma and is related to tumour grading. Int J Clin Exp Pathol 8: 8189-8198, 2015.

13. Ishida H, Kasajima A, Kamei T, Miura T, Oka N, Yazdani S, Ozawa Y, Fujishima F, Sakurada A, Nakamura Y, et al: SOX2 and Rb1 in esophageal small-cell carcinoma: Their possible involvement in pathogenesis. Mod Pathol 30: 660-671, 2017.

14. Ebisu Y, Ishida M, Okano K, Sandoh K, Mizokami T, Kita M, Okada $\mathrm{H}$ and Tsuta K: Small-cell neuroendocrine carcinoma in directly sampled endometrial cytology: A monocentric retrospective study of six cases. Diagn Cytopathol 47: 1297-1301, 2019.

15. Masai K, Tsuta K, Kawago M, Tatsumori T, Kinno T, Taniyama T, Yoshida A, Asamura $\mathrm{H}$ and Tsuda $\mathrm{H}$ : Expression of squamous cell carcinoma markers and adenocarcinoma markers in primary pulmonary neuroendocrine carcinomas. Appl Immunohistochem Mol Morphol 21: 292-297, 2013.

16. Yemelyanova A, Ji H, Shih IeM, Wang TL, Wu LS and Ronnett BM: Utility of p16 expression for distinction of uterine serous carcinomas from endometrial endometrioid and endocervical adenocarcinomas: Immunohistochemical analysis of 201 cases. Am J Surg Pathol 33: 1504-1514, 2009.

17. McCluggage WG, Kennedy K and Busam KJ: An immunohistochemical study of cervical neuroendocrine carcinomas: Neoplasms that are commonly TTF1 positive and which may express CK20 and P63. Am J Surg Pathol 34: 525-532, 2010.

18. Ordóñez NG: Value of PAX 8 immunostaining in tumor diagnosis: A review and update. Adv Anat Pathol 19: 140-151, 2012.

(i) $\Theta$ This work is licensed under a Creative Commons Attribution-NonCommercial-NoDerivatives 4.0 International (CC BY-NC-ND 4.0) License. 